\title{
Use of fish-borne camera to study chum salmon homing behavior in response to coastal features
}

\author{
Toshiya Kudo ${ }^{1}$, Hideji Tanaka ${ }^{2}$, Yuki Watanabe ${ }^{1}$, Yasuhiko Naito ${ }^{3}$, \\ Toshitake Otomo ${ }^{4}$, Nobuyuki Miyazaki ${ }^{1, *}$ \\ ${ }^{1}$ Ocean Research Institute, University of Tokyo Minamidai 1-15-1, Nakano-ku, Tokyo 164-8639, Japan \\ ${ }^{2} \mathrm{COE}$ for Neo-Science of Natural Science, Graduate School of Fisheries Science, Minato-cho 3-1-1, Hakodate, \\ Hokkaido 041-8611, Japan \\ ${ }^{3}$ National Institute of Polar Research \& Graduate University of Advanced Study 9-10, 1 Chome, Kaga Itabashi-ku, \\ Tokyo 173-8515, Japan \\ ${ }^{4}$ Iwate Prefecture Fisheries Technology Center 75-3, Jiwari 3, Hirata Oaza, Kamaishi-shi, Iwate 026-0001, Japan
}

\begin{abstract}
We used a fish-borne digital still-camera logger (DSL) to obtain visual information on surrounding environments encountered by homing chum salmon Oncorhynchus keta in the final period of migration at their southernmost distribution in Japan. Two salmon, a female and a male, were released with a DSL and were recovered $7 \mathrm{~h}$ and $8 \mathrm{~d}$ after release, respectively; we provide image data of their views. Of the underwater photos taken from the female and male, 99 and $88 \%$ (of a total 842 and 831 images), respectively, were taken in good light conditions. Both chum salmon visited the sea surface and sea floor but stayed in shallow water most of time. The salmon sometimes encountered floats of fishing gear, other chum salmon, Nomura's jelly fish, and other organisms, but very few scallop culturing rafts. The results suggest that the salmon swam in a group during this phase of the homing migration. The salmon were not attracted to farming gear (for shade or refuge), and in fact seemed to avoid it. The present study demonstrated that a fish-borne DSL is a useful and reliable tool for monitoring fish behavior and the relationship between their behavior and the surrounding environment.
\end{abstract}

KEY WORDS: Fish-borne camera - Chum salmon - Homing behavior - Artificial environment · Bio-logging Resale or republication not permitted without written consent of the publisher

\section{INTRODUCTION}

The pacific chum salmon Oncorhynchus keta is a typical anadromous fish. During September to December, they return to northern Japan from their foraging area in the Bering Sea, migrating for a few months at $>30 \mathrm{~km} \mathrm{~d}^{-1}$ (Tanaka et al. 2005). After their pelagic migration, they search for their natal river using directional odor cues once they reach coastal areas (Hasler et al. 1978). While chum salmon search for their natal river, they may encounter other organisms and artificial environments, such as fishing gear and floating rafts for marine aquaculture. How they react to coastal environments and manage their homing behavior is a principal concern with regard to the conservation and management of homing salmon. However, because of the technical difficulty involved in gathering such data, available information is scarce. Only Inoue et al. (1987), using scanning sonar, reported that most chum salmon avoided passing beneath the floating raft of seaweed and tended to detour to avoid the plants.

With regard to diving animals such as seals and penguins, several types of animal-borne image data loggers (video and still photo) have been developed to study their foraging behaviors. These data have been collected simultaneously with other behavior data, such as the depth, acceleration, and 3-dimensional dive paths, to learn how these animals approach and stalk 
their prey, and prey distribution (Davis et al. 1999, 2003, Ponganis et al. 2000, Hooker et al. 2002, Watanabe et al. 2003, 2004, 2006, and Mitani et al. 2004). Image data loggers have also been used for other studies such as social interaction (Sato et al. 2003, Takahashi et al. 2004) and behavioral avoidance as a result of diving sickness (Hooker et al. 2005). In recent years, the advanced animal-borne digital still-camera logger (DSL) system has helped to provide a better understanding of aquatic-animal behavior than was possible with previous techniques. However, the animal-borne DSL has never been used for smaller animals such as fish due to the large logger size, which is mostly determined by the size of the battery pack for the flash. Thus, we used this system without flash on homing chum salmon in a coastal bay area (this was possible because chum salmon are surface swimmers; Tanaka et al. 2000, 2001), which is narrower and where there is more potential for interaction than in open areas.

The purpose of this study was to obtain image data from homing chum salmon in a narrow bay area and to examine how chum salmon react to coastal environments.

\section{MATERIALS AND METHODS}

We conducted the experiment in Otsuchi Bay, located on the Pacific coast of Iwate Prefecture in northern Honshu, Japan, the southernmost migration area for chum salmon. Many set net fisheries operate along the coastal area of the bay, providing opportunities for the release and recapture of salmon (Fig. 1). We collected 8 homing adult chum salmon on 10
December 2003 from a salmon set net and kept them in a pond at the marine laboratory of the Ocean Research Institute, University of Tokyo. We selected (using the status of their nuptial color) a mature female salmon (031212 — body size: $74.5 \mathrm{~cm}$, body mass: $5.3 \mathrm{~kg}$ ) and a mature male (031218-body length: $72.5 \mathrm{~cm}$, body mass: $5.0 \mathrm{~kg}$ ), lightly anesthetized them with 2-phenoxy ethanol, and measured their body length and body mass. The applied immobilization and deployment techniques were permitted by the University of Tokyo (UT: 007). A DSL without flash (see paragraph below) was attached to the fish, which were then transferred to a tank and allowed to recover for $\sim 50 \mathrm{~min}$ from the anesthesia and surgery. Following this, they were transferred to a boat and released in the center of Otsuchi Bay (Fig. 1).

The DSL (Sanyo CCD iGT99263 image sensor camera, Little Leonardo) was mounted and fixed on the front of the dorsal fin using a polycarbonate net and nylon ties. The dimensions and weight were: diameter: $21 \mathrm{~mm}$; length: $138 \mathrm{~mm}$; air weight: $73 \mathrm{~g}$ (1.38 to $1.46 \%$ of salmon body mass); and it contained depth (resolution: $0.1 \mathrm{~m}$, range: 0 to $380 \mathrm{~m}$ ) and temperature (range: -20 to $50^{\circ} \mathrm{C}$ ) sensors. An automatic gain control (AGC) regulated exposure in order to maximize the contrast of the photo. The camera focus was fixed at infinity, and the nearest sight was $15 \mathrm{~cm}$. The camera could store $\sim 1300$ photos with a 370 (horizontal) $\times 296$ (vertical) pixel resolution in a $256 \mathrm{MB}$ flash memory. The camera was incased in a black anti-oxidized aluminum cylinder and was waterproof to $600 \mathrm{~m}$ depth; its specific gravity of 1.0 minimized the effect on fish movement. The sampling intervals were set at $30 \mathrm{~s}$ for digital images and at $1 \mathrm{~s}$ for depth and temperature.

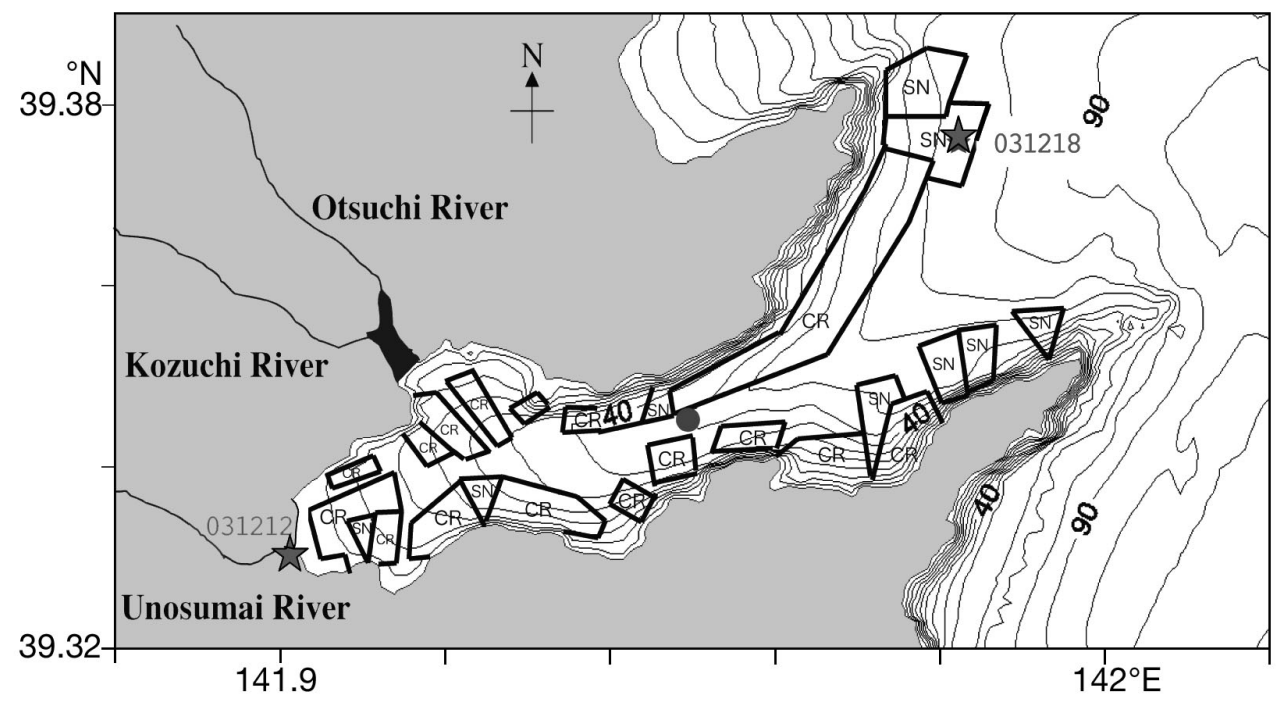

Fig. 1. Otsuchi Bay. Outer bay area is relatively deep (isobaths shown at $10 \mathrm{~m}$ intervals) and steep, and 3 small rivers run into the inner area of the bay. Points of release (solid circle) and recapture (star with identification no.) for both salmon are shown; SN and CR: areas for set nets and shell cultures, respectively 
Table 1. Oncorhynchus keta. Categorization of data from stillcamera loggers on the back of 2 adult homing chum salmon (ID Nos. 031212: female; 031218: male), which took 831 and 842 underwater photos, respectively, in Otsuchi Bay, Japan. Photos classified into 3 categories by their brightness and further categorized by position in the water column. Objects in photos classified into 4 categories: fishing gear (includes acquaculture rafts), fish, unidentified organisms and the set net in which the salmon were trapped. Frequency with which the objects appeared in the photos taken in the set net is shown

\begin{tabular}{|c|c|c|c|c|}
\hline & \multicolumn{2}{|c|}{$\begin{array}{l}\text { Female } \\
031212\end{array}$} & \multicolumn{2}{|c|}{$\begin{array}{c}\text { Male } \\
031218\end{array}$} \\
\hline & (n) & $(\%)$ & (n) & $(\%)$ \\
\hline \multicolumn{5}{|l|}{ Photo category } \\
\hline Dark & 11 & 1.3 & 102 & 12.3 \\
\hline Bright & 831 & 98.7 & 729 & 87.7 \\
\hline Total & 842 & 100 & 831 & 100 \\
\hline \multicolumn{5}{|c|}{ Position in water column } \\
\hline \multicolumn{5}{|l|}{ Mid-water } \\
\hline Shadows & 197 & 23.4 & 7 & 0.9 \\
\hline Non-shadows & 617 & 73.3 & 678 & 93 \\
\hline Surface & 26 & 3.1 & 28 & 3.8 \\
\hline Floor & 2 & 0.2 & 16 & 2.2 \\
\hline \multicolumn{5}{|l|}{ Object category } \\
\hline Gear & 3 & - & 6 & - \\
\hline Fish (salmon) & 8 & - & 0 & - \\
\hline Other organisms & 0 & - & 1 & - \\
\hline Set net & 186 & - & 0 & - \\
\hline Total & 197 & - & 7 & - \\
\hline \multicolumn{5}{|l|}{ Objects in set net } \\
\hline Salmon & 29 & - & - & - \\
\hline Jellyfish & 4 & - & - & - \\
\hline Small fish & 1 & - & - & - \\
\hline Non-organisms & 331 & - & - & - \\
\hline Total & 365 & - & - & - \\
\hline
\end{tabular}

Because of the lack of a light source, the digital camera was set to complete its recording period before dusk of the same day.

After the recovery of the DSLs, to omit unusable dark photos we used darkness criteria based on the mean brightness value (256 graduation) obtained using Image $\mathrm{J}$ (Image Processing and Analysis in Java, http://rsb. info.nih.gov/ij/), and classified our image data into 2 categories: dark (unusable for analysis, brightness value $<125$ ) and bright (a good photo for use, brightness value $>125$ ). By examining whether sea surface or sea floor shadows were visible in the photos, we classified photos into 3 depth categories: mid-water, sea surface, and sea floor. From this, we could tell how often salmon visited the sea surface and sea floor. Mid-water photos with some shadows were further examined to identify the objects in the photos (Table 1). We also examined the depth data from the DSLs together with a topographical map to determine if salmon came into the shallow area of the bay where culturing rafts occur, or stayed in the central deep area of the bay (Fig. 1).

\section{RESULTS AND DISCUSSION}

We successfully recovered both fish with DSLs attached. The female salmon (031212) was recaptured in Unosumai River $7 \mathrm{~h}$ after release and the male salmon (031218) was recaptured at Okinoshima in a set net $8 \mathrm{~d}$ after release (Fig. 1). Distance between release and recapture point was 24.48 and $22.56 \mathrm{~km}$ for the female and male, respectively. As we expected, our results indicate that this camera logger system was very useful in obtaining underwater photos; $\sim 90 \%$ of the photos were clear enough to identify the subjects in them. Though the camera size was small we cannot fully eliminate any effects that its deployment may have on the behavior of the fish. Tanaka et al. (2005) used almost the same size swim speed logger $(21 \mathrm{~mm}$ in diameter and $90 \mathrm{~mm}$ long) for chum salmon for $67 \mathrm{~d}$ of their oceanic migration from the Bering Sea to Hokkaido. Although the logger used in our study is slightly longer than the pelagic one, the short duration of its deployment in this study $(7 \mathrm{~h}$ for the female and $8 \mathrm{~d}$ for the male) may have lessened the effect of its size.

In total, 1674 underwater photos were obtained (842 photos during $7.02 \mathrm{~h}$ for the female and 831 photos during $6.93 \mathrm{~h}$ for the male salmon). Only 11 (1.3\%) of the photos from the female salmon were in the dark category; the rest $(831,98.7 \%)$ were bright and clear. Corresponding figures for the male were 102 (12.3\%) dark and $729(87.7 \%)$ bright. The female salmon did not dive deep (mean \pm SD: $13.7 \pm 9.6 \mathrm{~m}$; maximum: $46.2 \mathrm{~m})$, and according to the DSL image data, she swam for $3.73 \mathrm{~h}$ in Otsuchi Bay before entering the set net, yet 447 photos were taken during this period. In addition, 365 photos were taken during a further $3.04 \mathrm{~h}$ in the set net. The male salmon dove deeper than the female (mean $\pm \mathrm{SD}$ : $46.1 \pm 33.4 \mathrm{~m}$; maximum: $106.5 \mathrm{~m}$ ) and showed different movements depending on the depth of the sea floor. The depth and the temperature profiles of the male suggest that this individual remained in the inner bay for only a few hours and then moved towards the deep outer bay area (Fig. 2).

Of all 197 mid-water photos of the female containing some shadows, 186 were taken after re-entry into the set net; before entering it, the DSL took only 11 photos containing shadows. Of these 11 photos, 3 were of scallops at the culture farm (Fig. 3a) and 8 were of salmon moving in the same direction (Fig. 3b). In the set net, the logger on this salmon took 29 photos of other chum salmon, 4 of Nomura's jelly fish (Stomolophus nomurai) (Fig. 3c) and 1 of small fish (Fig. 3f). A total of 331 photos contained no organisms: 186 were set net photos and nothing appeared in the remaining 145 photos. The DSL on the male also took few photos in mid-water that showed other objects or organisms, 

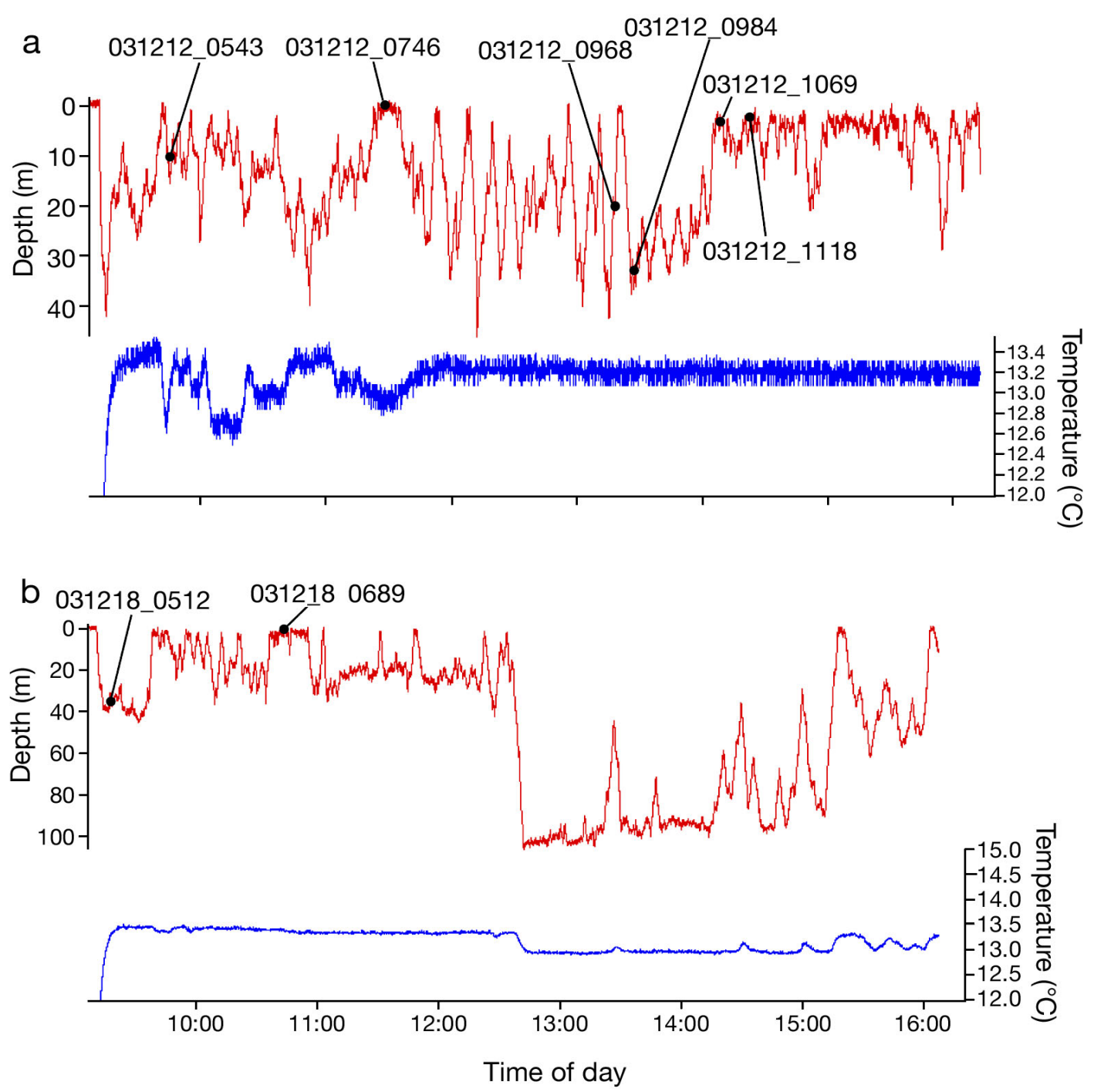

Fig. 2. Oncorhynchus keta. Depth and temperature profiles for the salmon (a) 031212: female, and (b) 031218: male, released into Otsuchi Bay on 10 December 2003. Numbers identify salmon, and point to time and depth at which the photos in Fig. 3 were taken. Though the male salmon was at liberty for $8 \mathrm{~d}$, data were recorded for only $\sim 7 \mathrm{~h}$

suggesting that this fish rarely encountered underwater objects. Out of 678 photos, 6 showed fishing floats and 1 showed small organisms, probably a group of small fish. His camera caught no other chum salmon images.

The present experiment was performed to examine how homing chum salmon react to obstacles like culturing rafts and fishing gear. Although the farming area with such items is restricted to the shallow area of the bay (Fig. 1), we had supposed that salmon would encounter the rafts at a high rate when they came into this area. However, the chum salmon showed a rather low encounter rate (Table 1), suggesting that they did not come into the farming area and were not attracted by the shade or refuge provided by the structures there. The fact that the rafts appeared only 3 times in 3 consecutive photos by the female (Fig. 3a) suggests that the salmon did not show a quick escape response to the raft, and that such rafts did not interrupt homing behavior except in the case of the set nets. A very low appearance rate of the floating raft of seaweed for the 2 salmon in this study may also suggest that chum salmon avoid them. This is similar to the result of Inoue et al. (1987). Homing chum salmon may have encountered other organisms, not by searching for prey, but by chance. Alternatively, mobile organisms like fish may have escaped and avoided encounters with the salmon.

Several photos showed other salmon swimming together with the female salmon in the same direction (Fig. 3b). These photos may suggest that salmon conduct their homing migration in small groups. Also 
031212-0543

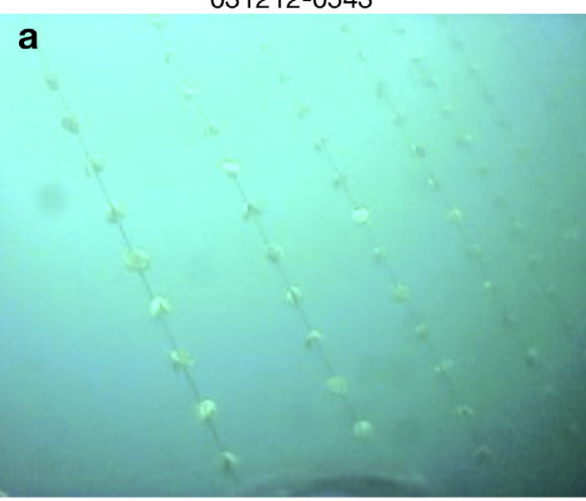

031218-0512

d

Fig. 3. Oncorhynchus keta. Example photos from fish-borne digital still-camera logger. $(\mathrm{a}-\mathrm{c})$ Female salmon encountering: (a) a scallop raft; (b) other salmon swimming in the same direction; (c) Nomura's jellyfish. (d,e) Male salmon visiting: (d) the sea floor; (e) the sea surface. (f) Small fish appeared only once in the set net, but $(g, h)$ other salmon appeared often. Numbers identify salmon and photo at time and depth shown in Fig. 2
031212-0746

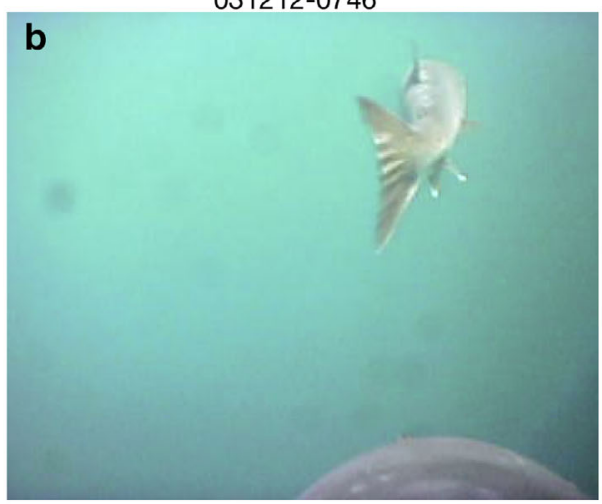

031218-0689

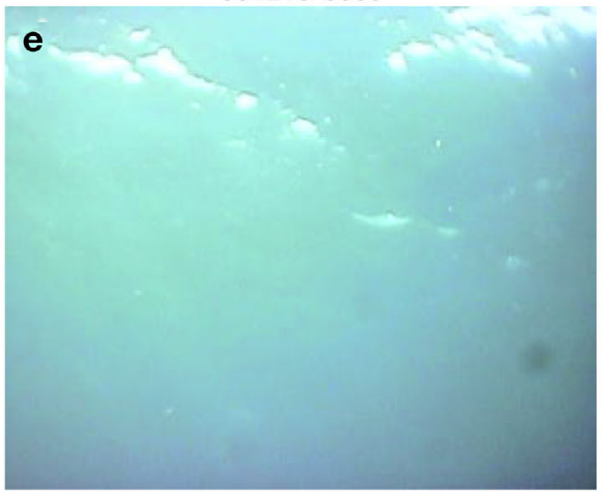

031212-1069

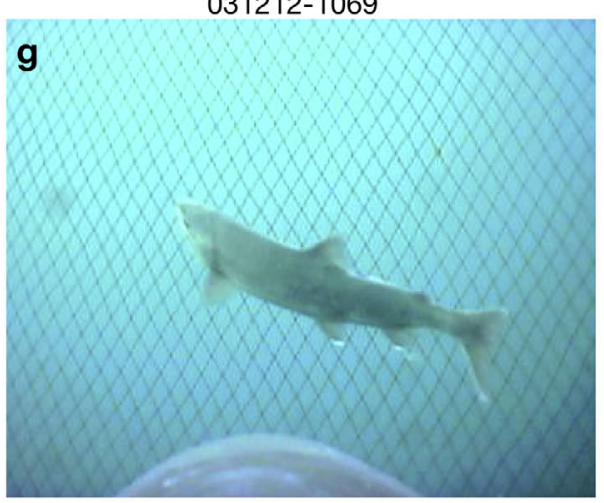

031212-0968

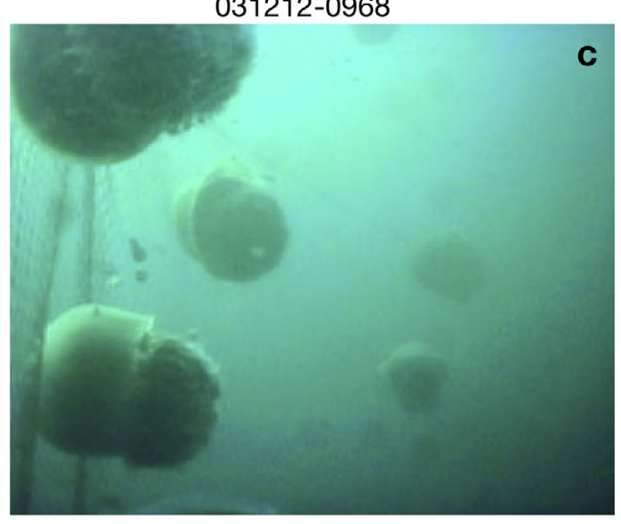

031212-0984

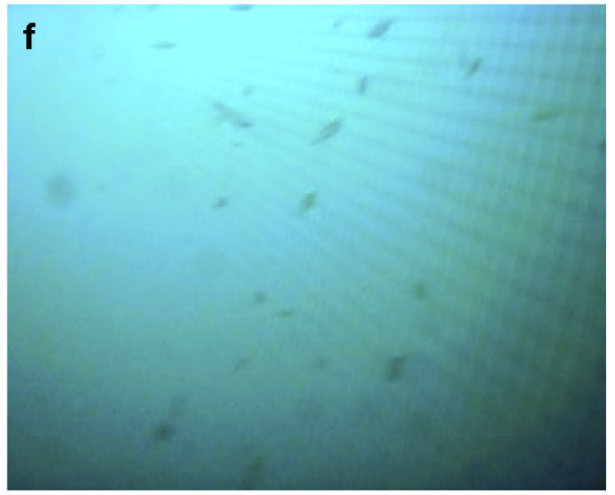

$031212-1118$

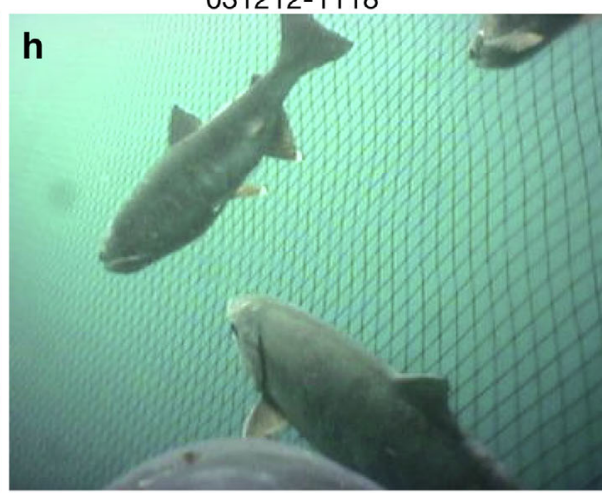

apparent was that both female and male salmon rarely visited the sea surface or sea floor (e.g. Fig. 3d,e). In the study area, homing chum salmon are known to take refuge in the bottom cooler layers (to depths of $\sim 150 \mathrm{~m}$ ) to lower their metabolic rate when the surface temperature is high and a prominent thermocline is present (Tanaka et al. 2000). However, in our study, the bottom depth that the salmon visited was very shallow and thus diving may not have served for thermoregulation. The bottom topography may have a role as a navigation aid. Judging from consecutive photos of the sea surface, they stayed at the surface for several minutes. Photos taken near the surface water column showed that the salmon came close to the sea surface but did not come out of the water. One possibility is that chum salmon may make sea-surface visits to detect fresh water runoff as an indicator of navigation to their natal river (Tanaka et al. 2000).

Acknowledgements: We thank the staff of the International Coastal Research Center, Ocean Research Institute, University of Tokyo. Special thanks go to Otsuchi Fishery Cooperative Union and Fisheries Research Center, Iwate Prefecture. The field experiments conformed to the provisions of the Protocol on Experimental Animals in the University of Tokyo, Japan. We received financial support from the Dream Construction Program of Iwate Prefecture, a Science Research Grant-in-Aid from the Japan Society for the Promotion of Science (14405027), and support from the Program of Biologging Science of the University of Tokyo (UTBLS). 


\section{LITERATURE CITED}

Davis RW, Fuiman LA, Williams TM, Collier SO and others (1999) Hunting behavior of a marine mammal beneath the Antarctic fast ice. Science 283:993-996

Davis RW, Fuiman LA, Williams TM, Horning M, Hagey W (2003) Classification of Weddell seal dives based on 3dimensional movements and video-recorded observations. Mar Ecol Prog Ser 264:109-122

Hasler A, Scholz AT, Horrall RM (1978) Olfactory imprinting and homing in salmon. Am Sci 66:347-355

Hooker SK, Boyd IL, Jessopp M, Cox O, Blackwell J, Boveng PL, Bengtson JL (2002) Monitoring the prey-field of marine predators: combining digital imaging with datalogging tags. Mar Mamm Sci 18:680-697

Hooker SK, Miller PJ, Johnson MP, Cox OP, Boyd IL (2005) Ascent exhalations of Antarctic fur seals: a behavioural adaptation for breath-hold diving? Proc R Soc Lond B Biol Sci 272:355-363

Inoue Y, Nagahora S, Watanabe T (1987) Variation of fish behavior infuenced by the construction of the set net. Nippon Suisan Gakkai Shi 53:695-698 (in Japanese)

Mitani Y, Watanabe Y, Sato K, Cameron MF, Naito Y (2004) 3D diving behavior of Weddell seals with respect to prey accessibility and abundance. Mar Ecol Prog Ser 281: 275-281

Ponganis PJ, Van Dam RP, Marshall G, Knower T, Levenson DH (2000) Sub-ice foraging behavior of emperor penguins. J Exp Biol 203:3275-3278

Editorial responsibility: Otto Kinne (Editor-in-Chief), Oldendorf/Luhe, Germany
Sato K, Mitani Y, Kusagaya H, Naito Y (2003) Sychronous shallow dives by Weddell seal mother-pup pairs during lactation. Mar Mamm Sci 19:384-395

Takahashi A, Sato K, Naito Y, Dunn MJ, Trathan PN, Croxall JP (2004) Penguin-mounted cameras glimpse underwater group behaviour. Proc R Soc Lond B Biol Sci 271: S281-S282

Tanaka H, Takagi Y, Naito Y (2000) Behavioural thermoregulation of chum salmon during homing migration in coastal waters. J Exp Biol 203:1825-1836

Tanaka H, Takagi Y, Naito Y (2001) Swimming speeds and buoyancy compensation of migrating adult chum salmon Onchorhynchus keta revealed by speed/depth/acceleration data logger. J Exp Biol 204:3895-3904

Tanaka H, Naito Y, Davis ND, Urawa S, Ueda H, Fukuwaka $M$ (2005) First record of the at-sea swimming speed of a Pacific salmon during its oceanic migration. Mar Ecol Prog Ser 291:307-312

Watanabe Y, Mitani Y, Sato K, Cameron MF, Naito Y (2003) Dive depths of Weddell seals in relation to vertical prey distribution as estimated by image data. Mar Ecol Prog Ser 252:283-288

Watanabe Y, Baranov EA, Sato K, Naito Y, Miyazaki N (2004) Foraging tactics of Baikal seals differ between day and night. Mar Ecol Prog Ser 279:283-289

Watanabe Y, Bornemann H, Liebsch N, Plötz J, Sato K, Naito Y, Miyazaki N (2006) Seal-mounted cameras detect invertebrate fauna on the underside of an Antarctic ice shelf. Mar Ecol Prog Ser 309:297-300

Submitted: May 8, 2007; Accepted: September 21, 2007

Proofs received from author(s): September 29, 2007 